\title{
Parenting Self-Construals of Mothers With a Serious Mental IIIness: Efficacy, Burden, and Personal Growth ${ }^{1}$
}

\author{
DAPHNA OYSERMAN ${ }^{2}$ \\ University of Michigan
}

\author{
DEBORAH BYBEE \\ Michigan State University
}

\author{
CAROL MOWBRAY AND SANG KYOUNG KaHNG \\ University of Michigan
}

\begin{abstract}
We explored parenting self-construals among mothers with serious mental illness $(n=$ 379). Mothers reported feeling moderately positively about themselves as parents, more efficacious than inefficacious, more positive than negative, more valued than disvalued; but also at least somewhat restricted and burdened by motherhood. Factor analyses revealed 3 parenting self-construal factors: efficacious, burdened, and parenting as a personal growth experience. In hierarchical regression analyses, parenting self-construal factors significantly added to prediction of parenting behaviors and attitudes (nurturance, explanatory parenting style, and parenting stress), once demographic, mental health history, and current social context variables (support, stress, and current mental health) were taken into account. Maternal parenting self-efficacy increased (while self-construal of parenting as a burden decreased) positive parenting style.
\end{abstract}

Parenting is like a shock therapy; it changes you and wakes you up.

- Mother receiving community-based treatment for serious mental illness

Motherhood is central both to how others define women and how women define themselves (Phoenix \& Woolett, 1991). In our individualistic society, becoming a parent and being a mother can be seen as a form of personal growth and development, central to the person one will become. Yet, clearly, motherhood is not simply a personal growth experience; it can also be burdensome.

1This research was funded by NIMH Grants R01MH54321 and R01MH57495 to Oyserman, Mowbray, and Bybee; Oyserman is also grateful for the support of the Center for Advanced Studies in the Behavioral Sciences.

${ }^{2}$ Correspondence concerning this article should be addressed to Daphna Oyserman, Institute for Social Research, The University of Michigan, Ann Arbor, MI 48106-1248. E-mail: daphna .oyserman@umich.edu

\section{3}

Journal of Applied Social Psychology, 2004, 34, 12, pp. 2503-2523.

Copyright (C) 2004 by V. H. Winston \& Son, Inc. All rights reserved. 
Motherhood involves a dense web of socially prescribed everyday tasks, carried out in relative social isolation, for which mothers are assumed to take primary responsibility (Hoffnung, 1992). These tasks can be very difficult to do well, undermining mothers' confidence in their competence as parents, and reducing parenting capacity (Marshall, 1991). Social and contextual factorsincluding poverty, social stresses, and lack of social support-make the tasks of parenting more difficult and can also decrease mothers' beliefs about their own efficacy (Elder, Eccles, Ardelt, \& Lord, 1995; Huston, McLoyd, \& Coll, 1994). Moreover, maternal problems, including emotional and physical illness, also can affect parenting.

Particular emphasis has been placed on maternal mental illness as a risk factor for parenting (e.g., Cummings \& Davies, 1994; Goodman \& Brumley, 1990; Teti, Gelfand, Messinger, \& Isabella, 1995). Understanding the process by which mental health problems impact parenting quality is important. Depression is common among women of childbearing age (Puckering, 1989), especially among nonworking mothers of preschool children. Nearly $50 \%$ of the population has been found to meet diagnostic criteria for a mental illness diagnosis over their lifetimes (Kessler et al., 1994). At any given point in time, $9 \%$ to $20 \%$ of the population report significant symptoms of depression, and once diagnosed, women commonly experience recurrent episodes (average 5 to 6 episodes per lifetime) and residual symptoms of anxiety, dysphoric mood, marital problems, and impaired social functioning, even after an apparent recovery (Hammen, 1991).

While maternal psychopathology alone may not make a parent incapable of providing sufficient or "good-enough" parenting, maternal mental illness is likely to co-occur with other stressors that also affect parenting adversely. These commonly co-occurring stressors include low income (Rudolph, Larson, Sweeny, Hough, \& Arorian, 1990), larger than average family size (Mowbray, Oyserman, \& Ross, 1995; Mowbray, Oyserman, Saunders, \& Rueda-Riedle, 1998; Ritsher, Coursey, \& Farrell, 1997), lack of social support (Belle, 1990), increased incidence of other negative life events (Downey \& Coyne, 1990), and the experience of social stigma and discrimination as a result of mental illness (Miller \& Finnerty, 1996; Ritsher et al., 1997). Thus, although economic and social stress should not be mistaken for problems as a result of mental illness, these stresses are likely to be bundled (Hill, 1996; Puckering, 1989) and collectively may elevate parenting stress and reduce parenting effectiveness (McLoyd, Jayaratne, Ceballo, \& Borquez, 1994).

Yet, poverty, mental health problems, social stress, and lack of social support do not always result in inadequate parenting (e.g., Kalil \& Eccles, 1998). Some literature has indicated that parents with a mental illness may feel competent as parents and function adequately at home, even if they are highly anxious and have difficulties in out-of-home situations, such as school or the workplace (Hall, 1996; Jacobsen, Miller, \& Kirkwook, 1997). 
How do some parents cope with stresses and manage to provide adequate parenting, in spite of these conditions? One possibility is that parenthood may not always be perceived as a burden, even in stressing conditions. Mothers may see parenthood as a chance to be competent and efficacious in a valued social role. Alternatively, they may see parenthood as a chance to receive support for personal growth. Personal identity and self-concept research indicates that personal meanings can buffer stress and affect role performance (Markus \& Wurf, 1987). Parents' sense of competence and efficacy, versus feelings of being burdened by the responsibilities of care giving, can be an important buffer from the negative impact of stress on parental nurturance and the sense of being burdened by the parenting role (for a review, see Coleman \& Karraker, 1998).

Parents who feel efficacious should be able to combine knowledge about what to expect of their children and how to respond appropriately to diverse parenting situations, with feelings of confidence in their ability to perform these parenting behaviors competently (Ozer \& Bandura, 1990). Parents who feel efficacious thus may be better able to avoid feeling overwhelmed and overburdened by the tasks of parenting, and to feel positively about parenting as a social role (Edin, 2000a, 2000b). Mothers who feel effective may be not only more warm and nurturing, but also more able to provide appropriate explanation to their children so that structure is not felt to be punitive.

Indeed, there is some evidence that maternal efficacy and confidence are beneficial. Conrad, Gross, Fogg, and Ruchala (1992) found that increased parenting confidence correlates positively with improved mother-toddler interactions, while abusive parenting is associated with low maternal efficacy (Bugental, Blue, \& Cruzcosa, 1989). Higher parenting efficacy correlates with fewer reported symptoms of depression, anxiety, and emotional distress in mothers (Gondoli \& Silverberg, 1997), and parenting efficacy may mediate the negative effects of maternal depression on mother-infant interactions (Teti \& Gelfand, 1991). Conversely, among mothers with low social support, those who were also lower in parenting efficacy were at greater risk of postpartum depression among mothers (Cutrona \& Troutman, 1986).

In spite of its potential significance, relatively little research has focused squarely on parents' voices in describing themselves as parents: their parenting self-construals as efficacious, burdened, or experiencing personal growth through childrearing. Rather, research has relied primarily on efficacy rating scales that have been criticized for low reliability and lack of validation in heterogeneous populations (Coleman \& Karraker, 1998), leading to a call for researchers to utilize measurement approaches other than structured questionnaire methods (Deater-Deckard, 1998). Indeed, a number of authors have described motherhood using a more naturalistic approach (Hoffnung, 1992; Woolett \& Phoenix, 1991), though these descriptions often involve primarily middle-class, married, White mothers. Little research to date has sought out the voices of parents in 
disadvantaged circumstances (for a review, see Coleman \& Karraker, 1998; Raver \& Leadbeater, 1999), even though such research is critical if we are to understand the mechanisms underlying positive parenting in disadvantaged households (Huston et al., 1994).

Following the literature, we hypothesize that parental self-construal content will relate to other aspects of parenting. Having an efficacious parental selfconstrual will relate to more positive parenting, as operationalized by higher maternal warmth and nurturance, more authoritative parenting style, and less parenting stress. Having a burdened parental self-construal will relate to parenting that is less warm, nurturing, and authoritative, accompanied by higher parenting stress. With regard to the alternative parental self-construal—parenthood as a personal growth experience - we were less sure of the likely impact on parenting. On the one hand, a focus on personal growth fits well with a self-actualizing focus, potentially promoting a high degree of interest, persistence, and motivation to succeed - all of which might promote nurturance, positive parenting style, and low parenting stress. On the other hand, parenting under conditions of poverty may not necessarily provide many positive, self-actualizing opportunities, so that focus on personal growth may increase parenting stress. Therefore, we felt a specific hypothesis was premature and simply explore the relationship between this aspect of parental self-construal and parenting.

In the current study of mothers with mental illness, we seek to ascertain how high-risk mothers feel about parenting and the parenting role, from their own perspective, using open-ended questions. Mothers' responses were coded and quantified, and the resulting variables were factor-analyzed to produce parenting self-construal dimensions, which were then used as independent variables in predicting parenting attitudes and behaviors.

\section{Method}

\section{Sample}

Participants were mothers with (a) regular care responsibility for at least one child 4 to 16 years of age and (b) a mental illness diagnosis documented by Community Mental Health Center records. All mothers were enrolled in some form of mental health service at the point of recruitment; either receiving outpatient services $(81 \%)$ or inpatient hospitalization $(19 \%)$ in a midwestern metropolitan area. A total of 485 mothers who met these criteria were contacted. Of these, 379 gave written consent to participate and were interviewed (of the remaining women, 46 could not be found after initial contact, and 59 refused participation), for a total response rate of $86 \%$ of those located. Mothers were 36.48 years old, on average $(S D=6.60)$, and had an average of 2.86 children $(S D=1.53)$. Two thirds $(n=258)$ of the mothers were living below the poverty line; $80 \%$ were not 
employed in the month prior to the interview, and $35 \%$ had not completed high school. Median age of mental illness onset was 26.68 years; median number of lifetime hospitalizations for mental illness was $2(M=4.25 ; S D=7.44)$; and 121 (32\%) participants reported psychiatric hospitalization in the past year. Interviews took place a month or more post-discharge to ensure that the mother's situation had restabilized.

\section{Study Procedure}

Data were collected through two at-home interviews scheduled no more than 2 weeks apart, with the second interview focused on substance use and psychiatric diagnosis. Participants were reimbursed $\$ 15$ for each interview. Full data on both interviews were obtained from $89 \%$ of mothers ( $n=337 ; 14$ refused the second interview, and 28 participated but provided incomplete information). No differences were found between mothers who completed both interviews and those who did not. To insure interview quality, interviews were audiotaped and checked by the interview coordinator. All interviewers were women aged 23 to 45 years, with at least an undergraduate degree in a human service field. Interviewers were trained in administration of the interview schedule.

\section{Measures}

Demographic and clinical history control variables. Following the federal poverty line formula (U.S. Census Bureau, 1996), poverty was assessed by weighting total monthly family income $(M=\$ 1,211.82, S D=\$ 1,210.77)$ by the number of family members to obtain a percentage of income above poverty. Other demographic variables - maternal education in years $(M=11.90, S D=$ $2.28)$ and race, dichotomized for analyses as African American $(n=227)$ and non-African American (including 111 White, 30 Hispanic, 11 other)-were obtained through open-ended questions.

Diagnosis was assessed using the major depression, bipolar disorder, and schizophrenia sections of the Diagnostic Interview Schedule (DIS; Robins, Helzer, Croughan, \& Ratcliff, 1981). Reported analyses use a dichotomized variable - depression without psychotic features $(n=134)$ versus other diagnosesbecause initial analyses have shown that women with and without depression report different levels of functioning.

Substance use history was assessed using the Drug Abuse Screening Test (DAST; Skinner, 1982; $\alpha=.94)$, a 19-item checklist $(M=5.01, S D=4.76)$ with a standard cutoff score of 5 marking a history of drug or alcohol abuse. Following the standard criteria, mothers above the cutoff $(n=158)$ are considered to have a history of substance abuse, whereas those below the cutoff $(n=219)$ are not.

Current context variables. Daily hassles were assessed using the 21-item Hassles and Uplifts scale (Kanner, Coyne, Schaefer, \& Lazarus, 1981; Lazarus \& 
Folkman, 1984). Responses on the 4-point scale range from 1 (not at all a hassle) to 4 (a great deal of a hassle). For the analyses reported here, three daily hassles questions related explicitly to children or to parenting ("Children are hassles," "Children's school/day care is a hassle," and "Getting someone to watch children is a hassle") were removed from the scale to avoid redundancy with the parenting variables $(M=8.84, S D=3.83, \alpha=.85)$.

Social support was assessed as the sum of people available for positive support $(M=6.93, S D=3.49)$ using the Arizona Social Support Interview Schedule (Barrera, 1988). Because support from one person does not necessarily relate to support from another, internal consistency is not obtained for this sum measure.

Psychiatric symptomatology was assessed with the 14-item Colorado Symptom Index (Shern et al., 1994; $M=2.77, S D=0.84, \alpha=.90$ ). Responses on the 5-point scale range from 1 (never) to 5 (at least every day). This widely used psychiatric symptom index has been related to vocational rehabilitation (Laudet, Magura, Vogel, \& Knight, 2002) and physical health of individuals with mental illness (Salyers, Bosworth, Swanson, Lamb-Pagone, \& Osher, 2000).

Community functioning was assessed with the 18-item Functioning scale (Bybee, Mowbray, Oyserman, \& Lewandowski, 2003; $M=3.39, S D=0.54, \alpha=$ .80). Responses on the 5-point scale range from 1 (very difficult/hardly ever) to 5 (not at all difficult/frequently).

Number of hospitalizations in the prior year was assessed $(M=0.32, S D=$ $0.51)$. As is common practice with count variables, this count was logtransformed (Fox, 1997).

Parenting variables. Nurturance was assessed with the 13-item Parental Nurturance subscale of the Block Child Rearing Practices scale (Rickel \& Biasatti, 1982; $M=3.66, S D=0.33, \alpha=.80)$. Responses on this 4-point scale range from 1 (not at all) to 4 (very much). This widely used measure has been employed in studies connecting nurturance to children's cognitive development (Sommerfelt et al., 2000) and self-regulation (Mauro \& Harris, 2000).

Parenting stress was assessed with the 14-item Parental Stress Index (Abidin, $1990 ; M=2.51, S D=0.78, \alpha=.86)$. Responses on this 5-point scale range from 1 (not at all) to 5 (very much). This scale has been used for various populations connecting parenting stress with childrearing attitudes (Halpern, Brand, \& Malone, 2001), maternal social support satisfaction, and depression (Wanamaker \& Glenwick, 1998).

Parenting style was coded from four parenting scenarios describing a problematic child behavior: a temper tantrum in public (the child grabs candy at the checkout counter and begins to scream when the mother takes it away), stealing (the child and mother go to the store; when they return, she finds a toy in the child's pocket), disagreement about going to bed, and not following directions (the mother tells the child to keep a newly washed coat clean; the child comes home dirty; Stollack, Scholom, Kallman, \& Saturansky, 1973). Stollack et al.'s 
original scenarios were modified so that the scenarios all involve situations that are common for all parents and are not dependent on parents' socioeconomic status. For example, the scenario regarding not following directions was changed from getting just-cleaned clothes dirty finger-painting while the mother is in the basement doing laundry to getting a just-cleaned coat dirty while at school because mothers in our sample could not be assumed to have basements or washing machines. Participants were asked what they would do in this situation if this were their own child.

Coding followed Baumrind $(1978,1991)$. Baumrind operationalized authoritative parenting style as provision of appropriate explanation and negotiation. Therefore, two coders coded for explanatory parenting style, which was operationalized as provision of instructions to the child coupled with explanation. For example, in the bedtime situation, a sample response was "I would tell her it's time to take her nap because she needs her rest." In the temper tantrum in public scenario, "I'd calmly explain to her that she couldn't have the candy, we cannot afford it" $(M=2.22, S D=1.18, \kappa=.75)$.

Parenting self-construals. Mothers were asked six open-ended questions: (a) What would you say are the advantages of having children and being a mother?

(b) Could you give me an example of something that makes you feel really good about being a mother? (c) What would you say are the disadvantages of having children and being a mother? (d) Could you give me an example of something that makes you feel bad about being a mother? (e) In what ways has motherhood changed your life? (f) What about being a mother is most important to you?

Response content across all six questions was rated for (a) overall negativity versus positivity, (b) inefficacy versus efficacy, (c) incompetence versus competence, (d) nonnurturance versus nurturance, (e) feeling disvalued versus valued, (f) feeling that one's context is supporting versus not supporting, (g) motherhood as personal growth, (h) motherhood as restrictive, (i) children as resources, and (j) children as a burden. For the unipolar variables (Variables g through $\mathrm{j}$ ), the codes ranged from 0 (no mention of relevant issues in maternal responses) to 3 (issue is brought up pervasively across components). For bipolar variables (Variables a through $\mathrm{f}$ ), the codes ranged from -3 (pervasive focus on the negative anchor) to +3 (pervasive focus on the positive anchor). Reliability was assessed for 50 randomly selected cases that were double-coded by two independent coders, blind to other information about the mothers. Spearman's rho for each variable is presented in Table 1. All final codes were obtained by consensus coding through discussion between the two trained coders.

Analysis Plan

First, we examined the content of mothers' parenting self-construals descriptively, followed by exploratory factor analyses (with varimax rotation) to reveal 


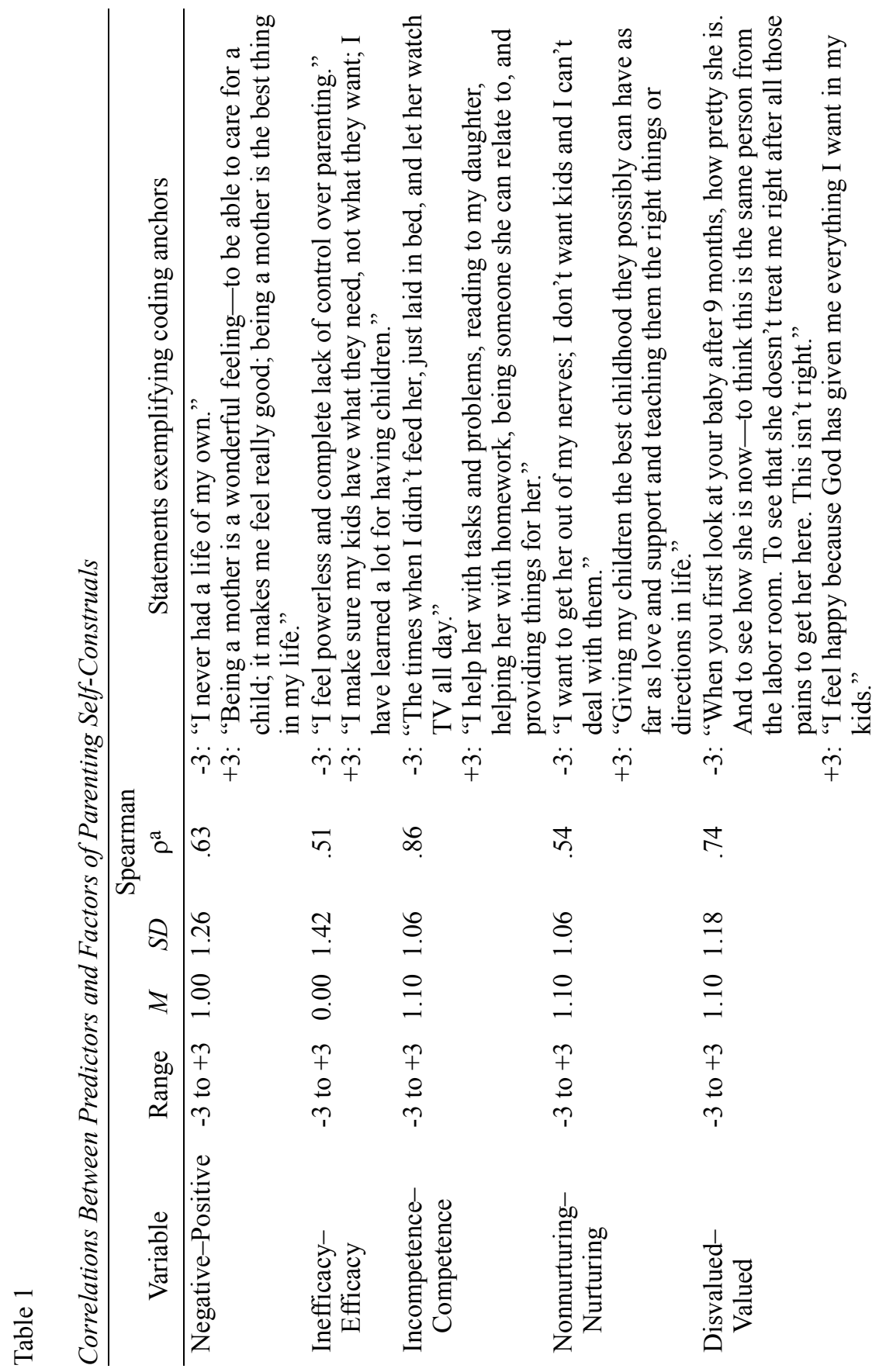




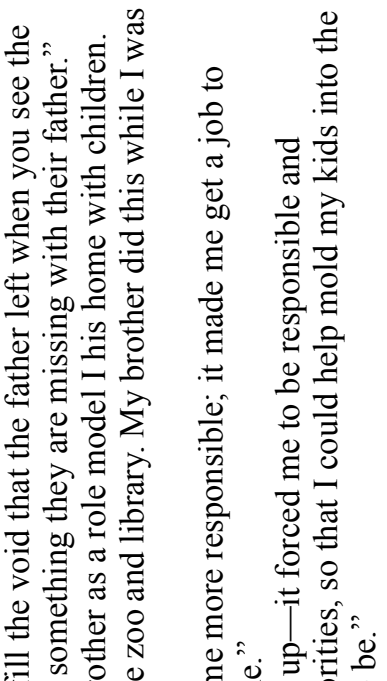

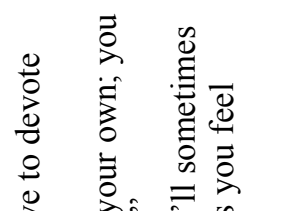

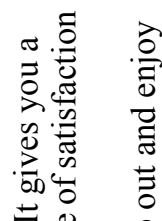

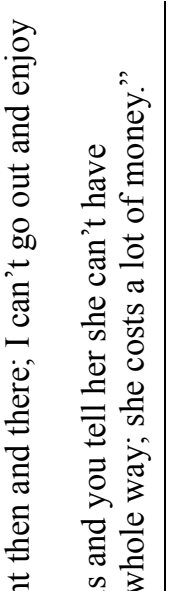

렁

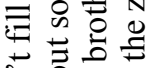

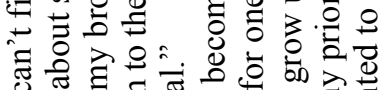

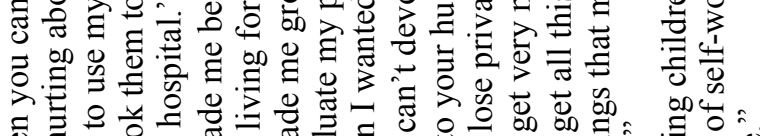

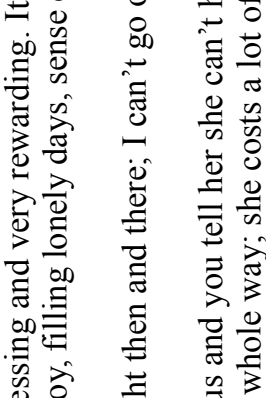

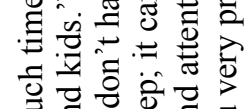

节

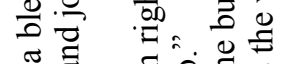

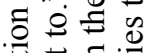

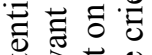

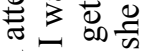

उ $\overrightarrow{0}$ oी

\&

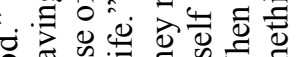

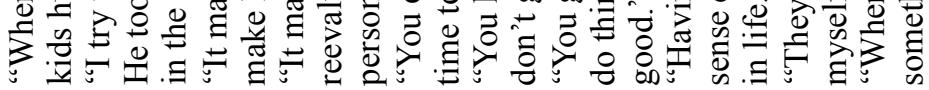

$\ddot{r} \ddot{\oplus} \ddot{\sim} \ddot{m} \ddot{-} \ddot{m} \ddot{-} \ddot{m} \ddot{-} \ddot{m}$

8

n

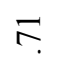

จ.

oิ

8

के

$\stackrel{8}{\circ}$

$\stackrel{\Xi}{g}$

के

웅

$\stackrel{\infty}{\circ}$

$\stackrel{8}{-}$

움

$\stackrel{8}{\circ}$

m

$\stackrel{1}{2}$

i

$\stackrel{9}{+}$

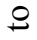

8

+

$+$

i)

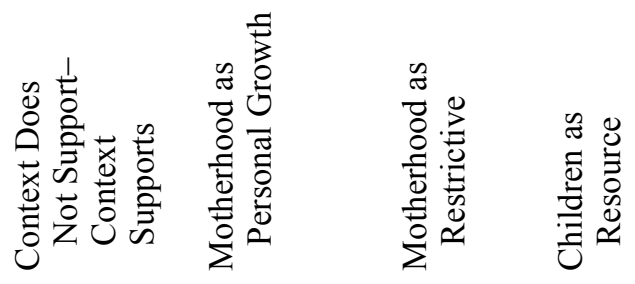

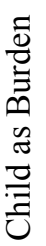

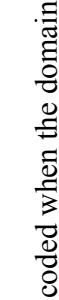

$\frac{2}{8}$

范

छัँ

(ำ

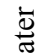

0

Ð

苟

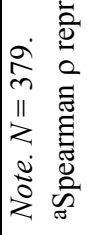


underlying factors. Next, we assessed the predictive power of the parenting selfconstrual factors in explaining variance in parenting nurturance, parenting stress, and parenting style once background (i.e., demographics, clinical history) and current status (i.e., social context, current mental health) variables had been taken into account. This set of analyses involved three hierarchical regression equations, with blocks ordered so that basic demographic variables (poverty status, maternal education, and ethnicity) and clinical history variables (diagnosis of mental illness and substance use history) were entered at Block 1. Current social context variables (daily hassles and social support) and current mental health variables (community functioning, number of hospitalizations in the previous year, and current psychiatric symptoms) were entered at Block 2. Hierarchical regression allowed us to examine the effect of the parenting self-construal factors controlling for the contributions of demographics, clinical history, and current context.

\section{Results}

\section{Descriptive Analyses}

Table 1 summarizes mean responses in each of the 10 content-rated domains. As can be seen, ratings were, on average, above the midpoint for the bipolar scales, though close to 1 on the 3-point positive range of each scale. The highest ratings were for efficacy, positivity, and feeling valued, though levels were moderate: Mothers averaged 1.42 for efficacy (vs. inefficacy), 1.26 for positivity (vs. negativity), and 1.18 for feeling valued (vs. disvalued). Similarly, for the unipolar scales, average ratings were moderate. For example, on average, mothers saw parenting as at least somewhat restrictive $(M=1.00)$ and children as somewhat of a burden $(M=0.69)$.

Thus, mothers expressed moderate levels of both positive and negative aspects of parenting. In order to study the relationship between these selfconstruals of parenting and parenting attitudes and behaviors, we conducted an exploratory factor analysis (varimax rotation) of the parenting self-construal items, which revealed three parenting self-construal factors-efficacious, burdened, and personal growth-explaining $56 \%$ of the item variance. Table 2 presents the factor loadings of the 10 self-construal ratings on the parenting self-construal factors. The efficacious factor focused on parenting construals as efficacious, competent, valued, positive, and nurturing; the burdened factor focused on parenting construals as burdened and parenting as restrictive; and the personal growth factor focused on parenting construals as personal growth, children as a resource, and social context as supporting parenting.

The bivariate correlations between parenting self-construal factors and other predictors included in regression analyses are summarized in Table 3. 
Table 2

Rotated Factor Loadings of Parenting Self-Construals

\begin{tabular}{lccc}
\hline \multicolumn{1}{c}{ Variable } & Efficacy & Burden & $\begin{array}{c}\text { Personal } \\
\text { growth }\end{array}$ \\
\hline Incompetence-Competence & .83 & .05 & .00 \\
Negative-Positive & .71 & -.41 & .24 \\
Inefficacy-Efficacy & .65 & .11 & .15 \\
Nonnurturing-Nurturing & .64 & -.29 & .12 \\
Disvalued-Valued & .60 & -.36 & .25 \\
Motherhood as Restrictive & .11 & .78 & -.11 \\
Children as Burden & -.29 & .68 & .03 \\
Context Constraining-Supporting & .01 & .24 & .82 \\
Children as Resource & .30 & -.29 & .51 \\
Motherhood as Personal Growth & .15 & -.25 & .49 \\
Total variance explained (\%) & 26 & 17 & 13 \\
\hline
\end{tabular}

Note. For ease of reading, variables are presented in order of their loading on their primary principal factor.

Hierarchical regression was utilized to examine whether parenting self-construals provided additional input about parenting behavior and attitudes once other relevant factors had been taken into account. We report the effects for parenting nurturance, parenting stress, and explanatory parenting style in the next sections.

\section{Nurturance}

As can be seen in the first column of Table 4, controlling for background (Block 1) and current status (Block 2), parenting self-construal factors (Block 3) added significantly to the prediction of parenting nurturance $\left(\Delta R^{2}=.09, p<.00\right)$. Specifically, parenting self-construal as efficacious was positively associated with nurturance $(b=.07, S E=.02, p<.00)$, and parenting self-construal as burdened was negatively associated with nurturance $(b=-.07, S E=.02, p<.00)$.

\section{Parenting Stress}

As can be seen in the second column of Table 4, controlling for the effect of background and current status, parenting self-construal factors added 
Table 3

Correlations Between Predictors and Factors of Parenting Self-Construals

\begin{tabular}{lccc}
\hline \multicolumn{1}{c}{ Variable } & Efficacy & Burden & $\begin{array}{c}\text { Personal } \\
\text { growth }\end{array}$ \\
\hline At or above poverty line & $.11^{*}$ & .07 & $.14^{* *}$ \\
African American race & -.05 & $.11^{*}$ & -.08 \\
Maternal education & $.10^{*}$ & .08 & .02 \\
Depression diagnosis & .06 & .02 & -.09 \\
Substance use history & $-.14^{* *}$ & -.05 & .06 \\
Daily hassles & .00 & .07 & .04 \\
Social support available & $.18^{* * *}$ & .01 & .04 \\
Community functioning & $.24 * * *$ & -.04 & .02 \\
Number of hospitalizations last year & .02 & -.05 & .05 \\
Psychiatric symptoms & $-.18^{* * *}$ & -.07 & -.03 \\
\hline
\end{tabular}

Note. $N=379$.

${ }^{*} p \leq .05 .{ }^{*} p \leq .01 .{ }^{* * *} p \leq .001$.

significantly to the prediction of parenting stress $\left(\Delta R^{2}=.12, p<.00\right)$. Specifically, parenting self-construals as efficacious and as personal growth each were related to reduced parenting stress $(b=-.17, S E=.04, p<.001$; and $b=-.08$, $S E=.04, p<.05$, respectively), while parenting self-construal as burdened was related to increased parenting stress $(b=.21, S E=.04, p<.001)$.

\section{Parenting Style}

As can be seen in the third column of Table 4, controlling for the effects of background and current status, parenting self-construal factors added significantly to prediction of parenting style $\left(\Delta R^{2}=.05, p<.01\right)$. Specifically, parenting self-construal as efficacious and as personal growth were each related to more explanatory parenting style $(b=.14, S E=.07, p<.05$; and $b=.14, S E=.06, p<$ .05 , respectively), while parenting self-construal as burdened was related to reduced explanatory parenting style $(b=-.17, S E=.06, p<.01)$.

\section{Discussion}

The current study explored parenting self-construals among women likely to experience a high load of stress as a result of a combination of low income, living 
in an urban context, being primarily single-parent mothers, having a history of a serious mental illness, and (for some) being African American. We sought first to ascertain how these mothers felt about parenting and the parenting role, then we explored the extent to which parenting self-construals add to the variance explained in parenting nurturance, stress, and style once demographic, clinical, and contextual factors have been taken into account.

Although maternal mental illness (particularly depression) is relatively common, little research has addressed how mothers with mental illness make sense of themselves as parents and what implications their self-construals have for parenting. Far from being perceived simply as a burden, qualitative research with low income (Edin, 2000a, 2000b; Jarrett, 1994) and mentally ill (Klehr, Cohler, \& Musick, 1983; Mowbray et al., 1995; Nicholson \& Blanch, 1994; Ritsher et al., 1997; Sands, 1995; White, Nicholson, Fisher, \& Geller, 1995) mothers has suggested that parenting is often central to these women's identities and that they are concerned about being effective parents. Indeed, it has been argued that parenting self-construals may be important proximal predictors of quality of parenting in conditions of stress (Raver \& Leadbeater, 1999).

We found that mothers differed in the extent to which they focused on parenting in terms of the experience of efficacy, burden, and personal growth. Though generally single, poor, and mostly minorities, mothers in our sample did not simply report feeling burdened by parenthood. Many also reported feeling efficacious or viewed parenting as a personal growth experience. These more positive parenting self-construals were predictive of the kinds of parenting behaviors and parenting style known to be promotive of beneficial outcomes for youth.

In terms of predicting parenting attitudes and behaviors from parenting selfconstrual factors, we found that mothers whose parenting self-concept focused on efficacy were more likely to be nurturant, less stressed by parenting, and more explanatory in their parenting style. Mothers whose parenting self-concept focused on burden were less nurturant, more stressed about parenting, and less explanatory. When faced with child misbehavior, they simply responded without explaining to the child their reasoning (e.g., what the child had done wrong, what the mother wanted the child to stop doing or start doing and why). Interestingly, mothers whose parenting self-concept focused on parenthood as a personal growth experience were also less stressed about parenting and used a more explanatory style. Literature to date has not differentiated sufficiently between feelings of stress and burden, feelings of efficacy, or focus on personal growth as part of parenting self-construals. The notion that mothers can be both burdened by parenting and also feel relatively efficacious as parents and feel that motherhood provides for personal growth warrants further exploration. If efficacy, burden, and personal growth do, indeed, have separate effects, this suggests that each should be addressed in preventive or parenting support interventions. 


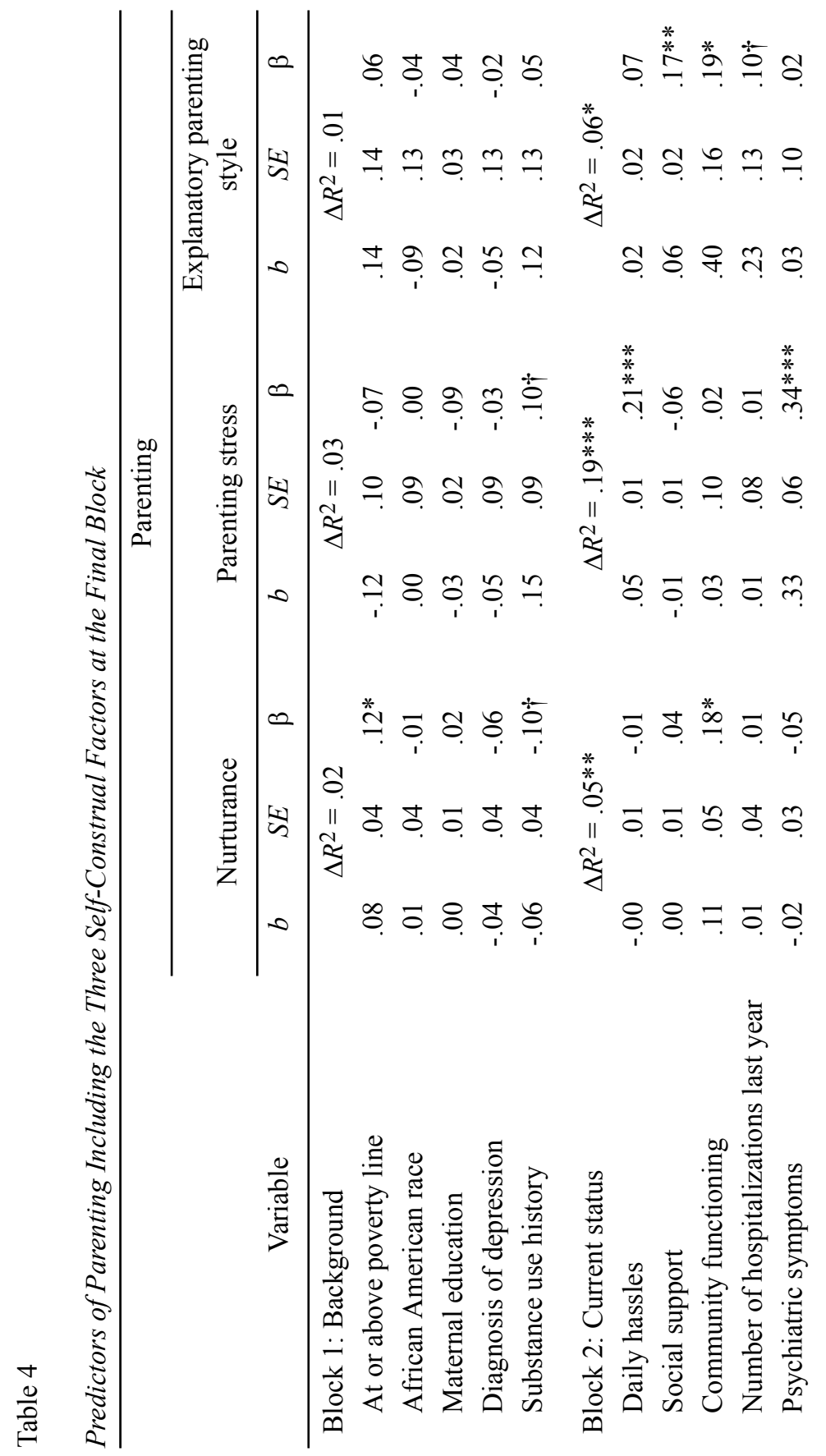


PARENTING SELF-CONSTRUALS 2517

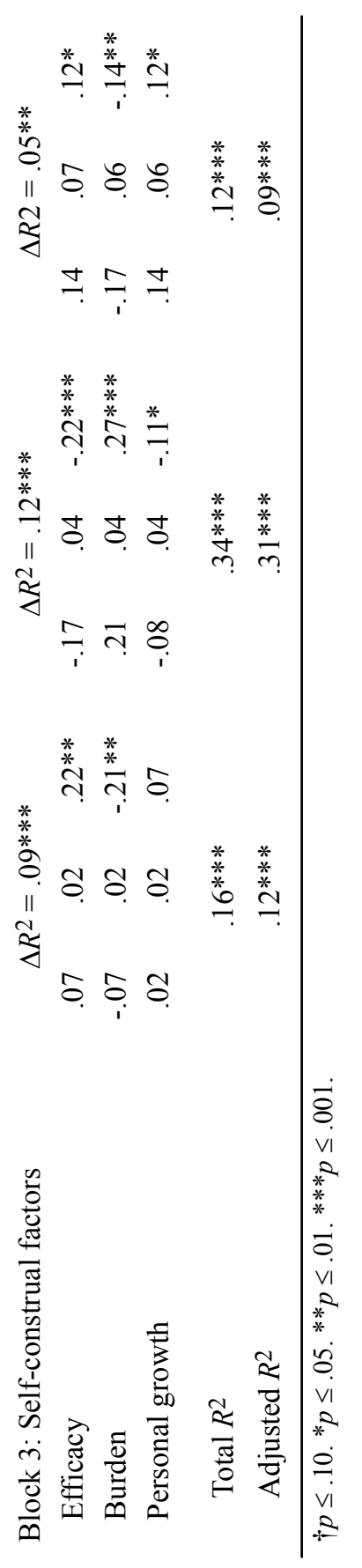


Clearly, the cross-sectional nature of the current analyses limits our ability to make causal inferences about the effect of parenting self-construals on parenting behaviors and attitudes. It is likely that many of the effects described are interactive or cyclical in nature, so that mothers' self-construals are shaped not only by social context, but also by previous experience. Further, self-construals can possibly influence future behavior and also mold some aspects of social context over time. Personality researchers have shown that personality traits such as shyness versus aggressiveness influence life trajectories in part by molding the quality and nature of social contexts, life stresses, and accessible social supports over time (e.g., Caspi, 2000). With parenting and mental illness, too, it seems likely that over time, mothers who are more efficacious will be better able to seek out social support to aid them in their parenting, creating successful experiences that will further increase their feelings of efficacy. Parenting efficacy, like other forms of efficacy, may be based, in large measure, in previous positive experiences (e.g., Ozer \& Bandura, 1990).

That means that mothers who were more successful as parents in the past would be more likely to develop a sense of efficacy to face future parenting stresses. Interventions that are focused on supporting mothers in their parenting and that succeed in providing successful parenting experiences can help mothers develop a sense of self as competent to take on future parenting challenges, and in this way buffer future parenting stress. Though quality of parenting selfconstruals, particularly feelings of parenting efficacy, are likely to be compromised by adverse circumstances, including poverty (Raver \& Leadbeater, 1999) and lack of adequate social support (Silvern, 1988), mothers able to sustain a sense of efficacy are likely to function better as parents; in essence, buffering their children from these contextual stresses (Conger, 2000).

Moreover, our findings suggest that positive effects of efficacy and negative effects of burden are independent, so that intervention efforts could target both to separate advantage for participants. While less studied, focus on parenthood as a personal growth experience may provide mothers with a sense of optimism for future growth, even in the face of current or previous failures. This, too, could provide an important foundation for future research and intervention. The interplay between parenting circumstances, self-construals, attitudes, and behaviors is just beginning to be explored. We believe that such exploration should be fruitful for constructing effective interventions for high-risk mothers that can adequately address identity concerns as well as concrete parenting practices.

\section{References}

Abidin, R. R. (1990). Parental Stress Index: Manual (3rd ed.). Charlottesville, VA: Pediatric Psychological Press. 
Barrera, M. (1988). Notes on deriving network indices from the ASSIS. Tempe, AZ: Arizona State University.

Baumrind, D. (1978). Reciprocal rights and responsibilities in parent and child relations. Journal of Social Issues, 34, 179-196.

Baumrind, D. (1991). Effective parenting during the early adolescent transition. In P. A. Cowan \& M. Hetherington (Eds.), Advances in family research: Family transitions (Vol. 2, pp. 111-163). Hillsdale, NJ: Lawrence Erlbaum.

Belle, D. (1990). Poverty and women's mental health. American Psychologist, 45, 385-389.

Bugental, D. B., Blue, J., \& Cruzcosa, M. (1989). Perceived control over caregiving outcomes: Implications for child abuse. Developmental Psychology, 25, 532-539.

Bybee, D., Mowbray, C. T., Oyserman, D., \& Lewandowski, L. (2003). Variability in community functioning of mothers with serious mental illness. Journal of Behavioral Health Services and Research, 30, 269-289.

Caspi, A. (2000). The child is father of the man: Personality continuities from childhood to adulthood. Journal of Personality and Social Psychology, 78, 158-172.

Coleman, P. K., \& Karraker, K. H. (1998). Self-efficacy and parenting quality: Findings and future applications. Developmental Review, 18, 47-85.

Conger, R. (2000, June). How SES effects family functioning. In I. Sandler \& M. Arthur (Co-Chairs), Socioeconomic stress: Implications for prevention. Symposium conducted at the 8th annual meeting of the Society for Prevention Research, Montreal, Quebec, Canada.

Conrad, B., Gross, D., Fogg, L., \& Ruchala, P. (1992). Maternal confidence, knowledge, and quality of mother-toddler interactions: A preliminary study. Infant Mental Health Journal, 13, 353-363.

Cummings, E., \& Davies, P. (1994). Maternal depression and child development. Journal of Child Psychology and Psychiatry, 35, 73-112.

Cutrona, C., \& Troutman, B. (1986). Social support, infant temperament, and parenting self-efficacy: A mediational model of postpartum depression. Child Development, 57, 1507-1518.

Deater-Deckard, K. (1998). Parenting stress and child adjustment: Some old hypotheses and new questions. Clinical Psychology: Science and Practice, 5, 314-332.

Downey, G., \& Coyne, J. (1990). Children of depressed parents: An integrative review. Psychological Bulletin, 108, 50-76.

Elder, G. H., Eccles, J. S., Ardelt, M., \& Lord, S. (1995). Inner city parents under economic pressure: Perspectives on the strategies of parenting. Journal of Marriage and the Family, 57, 771-784.

Edin, K. (2000a, July). Fifth year presentation. Presented at the W. T. Grant Faculty Scholars Retreat, Sundance, UT. 
Edin, K. (2000b). What do low-income single mothers say about marriage? Social Problems, 47, 112-133.

Fox, J. (1997). Applied regression analysis, linear models, and related methods. Thousand Oaks, CA: Sage.

Gondoli, D., \& Silverberg, S. (1997). Maternal emotional distress and diminished responsiveness: The mediating role of parenting efficacy and parental perspective taking. Developmental Psychology, 33, 861-868.

Goodman, S. H., \& Brumley, H. E. (1990). Schizophrenic and depressed mothers: Relational deficits in parenting. Developmental Psychology, 26, 31-39.

Hall, A. (1996). Parental psychiatric disorder and the developing child. In M. Goepfert, J. Webster, \& M. V. Seeman (Eds.), Parental psychiatric disorder: Distressed parents and their families (pp. 17-41). Cambridge, UK: Cambridge University Press.

Halpern, L. F., Brand, K. L., \& Malone, A. F. (2001). Parenting stress in mothers of very-low-birth-weight (VLBW) and full term infants: A function of infant behavioral characteristics and child-rearing attitudes. Journal of Pediatric Psychology, 26(2), 93-104.

Hammen, C. (1991). Generation of stress in the course of unipolar depression. Journal of Abnormal Psychology, 100, 555-561.

Hill, J. (1996). Parental psychiatric disorder and the attachment relationship. In M. Gopfert, J. Webster, \& M. V. Seeman (Eds.), Parental psychiatric disorder: Distressed parents and their families (pp. 7-16). Cambridge, UK: Cambridge University Press.

Hoffnung, M. (1992). What's a mother to do? Conversations on work and family. Pasadena, CA: Trilogy.

Huston, A., McLoyd, V., \& Coll, C. G. (1994). Children and poverty: Issues in contemporary research. Child Development, 65, 275-282.

Jacobsen, T., Miller, L. J., \& Kirkwook, P. Q. (1997). Assessing parenting competence in individuals with severe mental illness: A comprehensive service. Journal of Mental Health Administration, 24, 189-196.

Jarrett, R. (1994). Living poor: Family life among single African American women. Social Problems, 41, 30-49.

Kalil, A., \& Eccles, J. (1998). Does welfare affect family processes and adolescent adjustment? Child Development, 69, 1597-1613.

Kanner, A. D., Coyne, J. C., Schaefer, C., \& Lazarus, R. S. (1981). Comparison of two modes of stress measurement: Daily hassles and uplifts versus major life events. Journal of Behavioral Medicine, 4, 1-39.

Kessler, R. C., McGonagle, K. A., Zhao, S., Nelson, C. B., Hughes, M., Eshleman, S., Wittchen, H., \& Kendler, K. S. (1994). Lifetime and 12-month prevalence of DSM-III-R psychiatric disorders in the United States. Archives of General Psychiatry, 51, 8-19. 
Klehr, K. B., Cohler, B. J., \& Musick, J. S. (1983). Character and behavior in the mentally ill and well mother. Infant Mental Health Journal, 4, 250-271.

Laudet, A. B., Magura, S., Vogel, H. S., \& Knight, E. L. (2002). Interest in and obstacles to pursuing work among unemployed dually diagnosed individuals. Substance Use and Misuse, 37, 145-170.

Lazarus, R. S., \& Folkman, S. (1984). Comparison of two models of stress measurements: Daily hassles versus major life events. Journal of Behavioral Medicine, 4, 1-39.

Markus, H., \& Wurf, E. (1987). The dynamic self-concept: A social psychological perspective. Annual Review of Psychology, 38, 299-337.

Marshall, H. (1991). The social construction of motherhood: An analysis of children and parenting manuals. In A. Phoenix, A. Woollett, \& E. Lloyd (Eds.), Motherhood: Meanings, practices, and ideologies (pp. 66-85). London, UK: Sage.

Mauro, C. F., \& Harris, Y. S. (2000). The influence of maternal child-rearing attitudes and teaching behaviors on preschoolers' delay of gratification. Journal of Genetic Psychology, 161, 292-306.

McLoyd, V. C., Jayaratne, T. E., Ceballo, R., \& Borquez, J. (1994). Unemployment and work among African American single mothers: Effects on parenting and adolescent socioemotional functioning. Child Development, 65, 562-589.

Miller, L. J., \& Finnerty, M. (1996). Sexuality, pregnancy, and child-rearing among women with schizophrenia-spectrum disorders. Psychiatric Services, 47, 502-506.

Mowbray, C., Oyserman, D., \& Ross, K. (1995). Parenting and the significance of children for women with a serious mental illness. Journal of Mental Health Administration, 22, 189-200.

Mowbray, C., Oyserman, D., Saunders, D., \& Rueda-Riedle, A. (1998). Women with severe mental disorders: Issues and service needs. In B. L. Levin, A. K. Blanch, \& A. Jennings (Eds.), Women's mental health services: A public health perspective (pp. 175-200). Thousand Oaks, CA: Sage.

Nicholson, J., \& Blanch, A. (1994). Rehabilitation for parenting roles for people with serious mental illness. Psychosocial Rehabilitation Journal, 18, 109-119.

Ozer, E. M., \& Bandura, A. (1990). Mechanisms governing empowerment effects: A self-efficacy analysis. Journal of Personality and Social Psychology, $58,472-486$.

Phoenix, A., \& Woolett, A. (1991). Motherhood: Social construction, politics, and psychology. In A. Phoenix, A. Woollett, \& E. Lloyd (Eds.), Motherhood: Meanings, practices, and ideologies (pp. 13-27). London, UK: Sage.

Puckering, C. (1989). Annotation: Maternal depression. Journal of Child Psychology and Psychiatry and Allied Disciplines, 30, 807-817. 
Raver, C., \& Leadbeater, B. (1999). Mothering under pressure: Environmental, child, and dyadic correlates of maternal self-efficacy among low-income women. Journal of Family Psychology, 13, 523-534.

Rickel, A., \& Biasatti, L. (1982). Modifications of the Block Child Rearing Practices. Journal of Clinical Psychology, 38, 129-134.

Ritsher, J. E. B., Coursey, R. D., \& Farrell, E. W. (1997). A survey on issues in the lives of women with severe mental illness. Psychiatric Services, 48, 1273-1282.

Robins, L. N., Helzer, J. E., Croughan, J., \& Ratcliff, K. S. (1981). National Institute of Mental Health diagnostic interview schedule: Its history, characteristics, and validity. Archives of General Psychiatry, 38, 381-389.

Rudolph, B., Larson, G., Sweeny, S., Hough, E., \& Arorian, K. (1990). Hospitalized pregnant psychotic women: Characteristics and treatment issues. Hospital and Community Psychiatry, 41, 159-163.

Salyers, M. P., Bosworth, H. B., Swanson, J. W., Lamb-Pagone, J., \& Osher, F. C. (2000). Reliability and validity of the SF-12 Health Survey among people with severe mental illness. Medical Care, 38, 1141-1150.

Sands, R. G. (1995). The parenting experience of low-income single women with serious mental disorders. Families in Society: The Journal of Contemporary Human Services, 76(2), 86-96.

Shern, D. L., Wilson, N. Z., Coen, A. S., Patrick, D. C., Foster, M., \& Bartsch, D. A. (1994). Client outcomes: II. Longitudinal client data from the Colorado Treatment Outcome Study. Milbank Quarterly, 72, 123-148.

Silvern, S. B. (1988). Continuity/discontinuity between home and early childhood education environments. Elementary School Journal, 89, 147-159.

Skinner, H. A. (1982). The Drug Abuse Screening Test. Addictive Behaviors, 7, 363-371.

Sommerfelt, K., Andersson, H. W., Sonnander, K., Ahlsten, G., Ellertsen, B., Markestad, T., Jacobsen, G., Hoffman, H. J., \& Bakketeig, L. (2000). Cognitive development of term small for gestational age children at five years of age. Archives of Disease in Childhood, 83, 25-30.

Stollack, G. E., Scholom, A., Kallman, J. R., \& Saturansky, C. (1973). Insensitivity to children: Responses of undergraduates to children in problem situation. Journal of Abnormal Child Psychology, 1, 169-180.

Teti, D. M., \& Gelfand, D. M. (1991). Behavioral competence among mothers of infants in the 1st year: The mediational role of maternal self-efficacy. Child Development, 62, 918-929.

Teti, D. M., Gelfand, D. M., Messinger, D. S., \& Isabella, R. (1995). Maternal depression and the quality of early attachment: An examination of infants, preschoolers, and their mothers. Developmental Psychology, 31, 364-376.

U.S. Census Bureau. (1996). Poverty thresholds in 1996, by size of family and number of related children under 18 years: Current Population Survey. Washington, DC: Author. 
Wanamaker, C. E., \& Glenwick, D. S. (1998). Stress, coping, and perceptions of child behavior in parents of preschoolers with cerebral palsy. Rehabilitation Psychology, 43, 297-312.

White, C. L., Nicholson, J., Fisher, W. H., \& Geller, J. L. (1995). Mothers with severe mental illness caring for children. Journal of Nervous and Mental Disease, 183, 398-403.

Woolett, A., \& Phoenix, A. (1991). Psychological views of mothering. In A. Phoenix, A. Woolett, \& E. Lloyd (Eds.), Motherhood: Meanings, practices, and ideologies (pp. 28-46). London, UK: Sage. 